\title{
The sound insulation of single leaf finite size rectangular plywood panels with orthotropic frequency dependent bending stiffness
}

\author{
Robin R. Wareing ${ }^{\text {a) }}$ \\ University of Canterbury, Mechanical Engineering, Private Bag 4800, Christchurch 8140, New Zealand \\ John L. Davy ${ }^{\text {b) }}$ \\ Royal Melbourne Institute of Technology (RMIT) University, GPO Box 2476, Melbourne, Victoria 3001, \\ Australia \\ John R. Pearse \\ University of Canterbury, Mechanical Engineering, Private Bag 4800, Christchurch 8140, New Zealand
}

(Received 13 January 2015; revised 2 January 2016; accepted 5 January 2016; published online 25 January 2016)

Current theories for predicting the sound insulation of orthotropic materials are limited to a small range of infinite panels. This paper presents a method that allows for the prediction of the sound insulation of a finite size orthotropic panel. This method uses an equation for the forced radiation impedance of a finite size rectangular panel. This approach produces an equation that has three nested integrals. The long numerical calculation times were reduced by using approximate formulas for the azimuthally averaged forced radiation impedance. This reduced the number of nested integrals from three to two. The resulting predictions are compared to results measured using two sample sizes of four different thicknesses of plywood and one sample size of another three different thicknesses of plywood. Plywood was used for all the tests because it is somewhat orthotropic. It was found during testing that the Young's moduli of the plywood were dependent on the frequency of excitation. The influence of the frequency dependent Young's moduli was then included in the prediction method. The experimental results were also compared with a simple isotropic prediction method. (C) 2016 Acoustical Society of America. [http://dx.doi.org/10.1121/1.4940125]

$[\mathrm{MV}]$

Pages: 520-528

\section{INTRODUCTION}

A large number of prediction methods exist for the prediction of the sound insulation of various different partitions. A number of authors have explored the prediction of the sound transmission loss based on single leaf panels (Cremer, 1942; London, 1949; Sewell, 1970). This was also expanded to incorporate double leaf partitions (London, 1950; Sharp, 1978). A major assumption made in a number of these early models was that the panel was of infinite extent. This condition is obviously not met in any real laboratory situations.

Despite the large quantity of research that has been undertaken by a wide range of authors, there are still significant gaps in the current understanding of sound insulation behaviour. Two comparative studies by Hongisto (2002, 2006) showed that the majority of the commonly used prediction methods were relatively limited in their applications and did not yield accurate results when compared to experimental results from a range of different partitions. Furthermore, the evaluated models were all limited to the prediction of partitions built using isotropic materials. An equivalent study has not been performed on prediction schemes that allow for orthotropic material properties.

\footnotetext{
${ }^{a)}$ Electronic mail: r.r.wareing@gmail.com

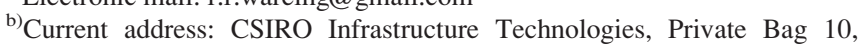
Clayton South, Victoria 3169, Australia.
}

Several other approaches have been utilised by different authors to predict the sound insulation of single and double leaf partitions. These include finite element analysis (Trevathan, 2005; del Coz Diaz et al., 2007; del Coz Diaz et al., 2010), statistical energy analysis (Crocker and Price, 1969; Fahy, 1994; Steel and Craik, 1994; Craik, 1996), and transfer matrix methods (Sastry and Munjal, 1995; Lee and $\mathrm{Xu}, 2009)$. These methods have achieved various levels of success, but were not investigated in the research presented here.

Several prediction methods presented by Hansen (1990, 1991) allow for the prediction of the sound insulation of highly orthotropic materials, corrugated sheets, for example. These materials are highly orthotropic; the stiffness in the hard direction that can be upward of ten times the stiffness in the soft direction. This has the effect of introducing two critical frequencies that are relatively widely separated. In contrast, plywood has a lower but still significant variation between the hard and soft stiffness parameters, causing the two critical frequencies to be closer together. This separation of the two critical frequencies results in two coincidence dips, with a region of reduced sound transmission loss between them.

A recent review of the vibro-acoustics of orthotropic laminates is D'Alessandro et al. (2013). This review references the papers of Guyader and Lesueur (1978a,b, 1980), along with many other papers. Two more recent papers on 
the sound transmission loss of orthotropic panels are those of Woodcock and Nicolas (1995) and Kuo et al. (2008).

Much of the recent research on orthotropic panels has studied panels with honeycomb cores rather than the solid ply cores considered in this paper, but there are many similarities in behaviour. Orrenius et al. (2010) compared theoretical predictions and experimental measurements of the wave number and sound reduction index of honeycomb core panels used in aircraft fuselages and train floors. Feng and Kumar (2012) studied the fact that current theories usually predict too low a sound reduction index in the critical frequency region. Cherif and Atalla (2015) have compared theoretical predictions of a general laminate model for wave number, damping loss factor, modal density, radiation efficiency, and sound reduction index with measurements often made with a number of different experimental techniques. They also derived the properties of an equivalent orthotropic panel model from the general laminate model. This equivalent orthotropic panel model was used to calculate the sound reduction index and gave better agreement with experiment for the thicker of the two honeycomb panels. The equivalent orthotropic model is used in this paper with measured properties.

The last two papers cited above each compare their theoretical predictions with two small sample size honeycomb core panels of different thickness. This paper compares its theoretical predictions with seven small sample size plywood panels of different thickness and four large sample size plywood panels of different thickness. Because plywood is not highly orthotropic, this paper also compares the experimental results with a simple isotropic model.

The prediction methods presented herein are built on the work undertaken by Ordubadi and Lyon (1979). The original publication by Ordubadi and Lyon presented a method for predicting the sound transmission loss of infinite orthotropic panels. In the article, plywood was also utilised as a test material due to its orthotropic nature. Ordubadi and Lyon (1979) achieved reasonable agreement between the measured and predicted results, although their prediction method did not use frequency dependent material properties or the finite size of the panel. This paper uses the radiation impedance of a finite size rectangular panel and an approximation to that radiation impedance with both constant and frequency dependent Young's moduli.

\section{MODEL DEVELOPMENT}

The blocked incident sound pressure on the source side at the surface of the rectangle specimen mounted in an infinite rigid baffle is $2 p_{i}$ due to the pressure doubling that occurs at the blocked surface for the plane wave sound wave with root-mean-square sound pressure $p_{i}$ incident with an angle of incidence $\theta$ to the normal to the specimen, and with an azimuthal angle $\phi$ to the $x$ axis. The transverse vibration of the specimen is accounted for by its radiation impedance $Z_{w}(\theta, \phi)$. The root-mean-square normal velocity $v(\theta, \phi)$ of the specimen is

$$
v(\theta, \phi)=\frac{2 p_{i}}{Z_{p}(\theta, \phi)+2 Z_{w}(\theta, \phi)},
$$

where $Z_{p}(\theta, \phi)$ is the bending wave impedance of the plate.

The incident sound intensity $I_{i}(\theta, \phi)$ in the direction normal to the specimen is

$$
I_{i}(\theta, \phi)=\frac{\left|p_{i}\right|^{2} \cos (\theta)}{\rho_{0} c},
$$

where $\rho_{0}$ is the ambient density and $c$ is the speed of sound of the compressible fluid on either side of the specimen. The $\cos (\theta)$ occurs because the projected area of the specimen seen from an angle of incidence of $\theta$ is proportional to $\cos (\theta)$.

The transmitted sound intensity $I_{t}(\theta, \phi)$ in the direction normal to the specimen is

$$
I_{t}=\operatorname{Re}\left[Z_{w}(\theta, \phi)\right]\left|\frac{2 p_{i}}{Z_{p}(\theta, \phi)+2 Z_{w}(\theta, \phi)}\right|^{2} .
$$

The sound transmission factor $\tau(\theta, \phi)$ is

$$
\begin{aligned}
\tau(\theta, \phi) & =\frac{4 \rho_{0} c \operatorname{Re}\left[Z_{w}(\theta, \phi)\right]}{\left|Z_{p}(\theta, \phi)+2 Z_{w}(\theta, \phi)\right|^{2} \cos (\theta)} \\
& =\frac{\operatorname{Re}\left[\frac{Z_{w}(\theta, \phi)}{\rho_{0} c}\right]}{\left|\frac{Z_{p}(\theta, \phi)}{2 \rho_{0} c}+\frac{Z_{w}(\theta, \phi)}{\rho_{0} c}\right|^{2} \cos (\theta)} .
\end{aligned}
$$

The total incident diffuse field sound intensity $I_{d i}$ is

$$
\begin{aligned}
I_{d i} & =\int_{0}^{\pi / 2} \int_{0}^{2 \pi} I_{i}(\theta, \phi) \sin (\theta) d \phi d \theta \\
& =\frac{\left|p_{i}\right|^{2}}{\rho_{0} c} \int_{0}^{\pi / 2} \int_{0}^{2 \pi} \cos (\theta) \sin (\theta) d \phi d \theta=\pi \frac{\left|p_{i}\right|^{2}}{\rho_{0} c} .
\end{aligned}
$$

The total transmitted diffuse field sound intensity $I_{t i}$ is

$$
\begin{aligned}
I_{d t} & =\int_{0}^{\pi / 2} \int_{0}^{2 \pi} \tau(\theta, \phi) I_{i}(\theta, \phi) \sin (\theta) d \phi d \theta \\
& =\frac{\left|p_{i}\right|^{2}}{\rho_{0} c} \int_{0}^{\pi / 2} \int_{0}^{2 \pi} \tau(\theta, \phi) \cos (\theta) \sin (\theta) d \phi d \theta
\end{aligned}
$$

The $\sin (\theta)$ term occurs in Eqs. (5) and (6) because the amount of solid angle at an angle of $\theta$ to the normal to the specimen is proportional to $\sin (\theta)$. The diffuse field sound transmission factor $\tau_{d}$ is

$$
\begin{aligned}
\tau_{d} & =\frac{I_{d t}}{I_{d i}}=\frac{1}{\pi} \int_{0}^{\pi / 2} \int_{0}^{2 \pi} \tau(\theta, \phi) \cos (\theta) \sin (\theta) d \phi d \theta \\
& =\frac{1}{\pi} \int_{0}^{\pi / 2} \int_{0}^{2 \pi} \frac{\operatorname{Re}\left[\frac{Z_{w}(\theta, \phi)}{\rho_{0} c}\right]}{\left|\frac{Z_{p}(\theta, \phi)}{2 \rho_{0} c}+\frac{Z_{w}(\theta, \phi)}{\rho_{0} c}\right|^{2}} \sin (\theta) d \phi d \theta .
\end{aligned}
$$


If the principal orthotropic axes and the sides of the rectangular specimen are parallel to each other and to the $x$ and $y$ axes, then by symmetry, the range of integration over the azimuthal angle $\phi$ can be reduced from the full circle to one quarter of the circle

$$
\tau_{d}=\frac{4}{\pi} \int_{0}^{\pi / 2} \int_{0}^{\pi / 2} \frac{\operatorname{Re}\left[\frac{Z_{w}(\theta, \phi)}{\rho_{0} c}\right]}{\left|\frac{Z_{p}(\theta, \phi)}{2 \rho_{0} c}+\frac{Z_{w}(\theta, \phi)}{\rho_{0} c}\right|^{2}} \sin (\theta) d \phi d \theta .
$$

The sound reduction index $R$ is

$$
R=-10 \log _{10}\left(\tau_{d}\right) \text {. }
$$

Thus, in order to derive an expression for the transmission coefficient of a partition, expressions for both the bending wave impedance and the radiation impedance must also be derived. The bending wave impedance of an orthotropic panel can be derived from the panel's equation of motion given by Leissa (1969). This yields the following expression for the orthotropic impedance as used by Ordubadi and Lyon (1979):

$$
Z_{p}(\theta, \phi)=\frac{k_{0}^{4} \sin ^{4}(\theta) B^{\prime}(\phi)-\rho_{s} \omega^{2}}{i \omega},
$$

where $k_{0}$ is the wave number of the incident wave, $\rho_{s}$ is the surface density of the panel, $\omega$ is the angular frequency of excitation, and $B^{\prime}(\phi)$ is the complex bending wave stiffness per unit width of the panel. The influence of the panel's internal damping is included in the stiffness parameter using the following equation:

$$
\begin{aligned}
B^{\prime}(\phi)= & \left(B_{x} \cos ^{4}(\phi)+B_{y} \sin ^{4}(\phi)\right. \\
& \left.+2 H \sin ^{2}(\phi) \cos ^{2}(\phi)\right)(1+i \eta),
\end{aligned}
$$

where $B_{x}$ and $B_{y}$ are the bending wave stiffness per unit width in the orthotropic principal axes directions, $H$ is a parameter for the orthotropic stiffness behaviour, and $\eta$ is the damping loss factor of the panel.

The frequency dependence of the bending stiffness properties can be incorporated by modifying Eq. (11). This yields the following expression:

$$
\begin{aligned}
B^{\prime}(\phi)= & {\left[B_{x}(f) \cos ^{4}(\phi)+B_{y}(f) \sin ^{4}(\phi)\right.} \\
& \left.+2 H(f) \sin ^{2}(\phi) \cos ^{2}(\phi)\right][1+i \eta],
\end{aligned}
$$

where $f$ is the frequency of excitation. In this paper, it was assumed that the damping loss factor was independent of frequency. The value of $H(f)$ is assumed to be the geometric mean of the two orthotropic bending stiffness values, as given by

$$
H(f)=\sqrt{B_{x}(f) B_{y}(f)} .
$$

The bending stiffnesses per unit width $B^{\prime}$ are derived from the Young's moduli $E$ using the following equation:

$$
B^{\prime}=\frac{E h^{3}}{12\left(1-\mu^{2}\right)},
$$

where $h$ is the thickness of the specimen and $\mu$ is Poisson's ratio, which is assumed to be 0.3 in this paper.

The dynamic Young's moduli of the test samples were measured in the two directions parallel to the grain of the wood plies using free-free beams that were excited via force impulses. The resonant frequencies and half power bandwidths of the modes of a number of different length beams were measured. This measurement technique allowed the frequency dependence of the Young's moduli of the plywood to be measured. The frequency dependent Young's moduli were found to be approximated reasonably using a best fit exponential decay with increasing frequency. The generic expression for this model of Young's modulus is given by

$$
E(f)=E_{i} e^{-Q f},
$$

where $E(f)$ is the frequency dependent stiffness, $E_{i}$ is the stiffness at zero frequency, and $Q$ is the rate of reduction of the stiffness parameter.

The accuracy of the model used for the frequency dependent Young's moduli has a significant impact on the predictions for the overall sound insulation. The method used to measure the dynamic Young's moduli in the research described in this paper provided relatively narrow bands of widely spaced clusters of data. The models for the frequency dependent Young's moduli were constructed from this data. This yielded models that may have had significant sources of error. This is one of the possible reasons why poor agreement may be obtained between prediction and experiment in some cases. The damping loss factor was also observed to vary with frequency, but this variation did not have a clear pattern that could be modelled effectively. Incorporating a frequency dependent damping loss factor would have a significant effect on the predicted sound insulation in and above the critical frequency region.

The finite specimen size was accounted for by using the equations for the finite panel traveling wave radiation impedance given by Davy et al. (2015a,c). These equations involve one numerical integration and are based on the work of Rhazi and Atalla (2010). Calculating the sound reduction index, when the numerical integration is used to calculate the finite size radiation impedance, requires the numerical evaluation of three nested integrals. This means large computational times especially at higher frequencies. Thus, the approximate equations of Davy et al. (2015a,b) for the azimuthally averaged finite size radiation impedance were also used to calculate the sound reduction index. It should be noted that the use of these approximate equations means that the finite size radiation impedance is assumed to be constant as a function of azimuthal angle. The use of these approximate equations reduces the number of nested integrals that have to be numerically evaluated from three to two, and substantially speeds up the calculations. The numerical integrations were performed using MATLAB's inbuilt adaptive 
numerical integration function, integral, which uses adaptive Simpson quadrature.

Because plywood is not highly orthotropic, a simple isotropic model (Davy, 2009a) was also used to calculate the sound reduction indices. The Young's modulus used was the geometric mean of the Young's moduli in the two orthotropic principal axes directions. It was noted that the low frequency sound reduction indices calculated with the isotropic model were systematically slightly lower than those calculated using the orthotropic methods described above. Examination of the isotropic model showed it was ignoring the fluid loading on the specimen. The fluid loading on the specimen is not significant for specimens with high sound insulation, but has a significant effect for specimens with low sound insulation at low frequencies like the thinner plywood specimens studied in this paper. The fluid loading was incorporated in the isotropic model by replacing Eq. (42) of Davy (2009a) with Eqs. (8) and (12) of Davy (2009b). The square root of $A$ in Eq. (12) of Davy (2009b) was replaced with the length $l$ of the side of the equivalent square given by

$$
l=\frac{2 l_{x} l_{y}}{l_{x}+l_{y}},
$$

where $l_{x}$ and $l_{y}$ are the lengths of the sides of the rectangular specimen.

\section{EXPERIMENTAL METHOD AND RESULTS}

The sound insulation of a range of plywood partitions were measured for comparison with the predicted results. The partitions tested were all single leaf systems that were tested in two sizes of sound insulation facilities. The test samples were installed between a reverberation room and a semianechoic room, and the intensity method was used for evaluating the sound transmission loss (ISO, 2000). The two sample sizes used were: $4.8 \times 2.4 \mathrm{~m}\left(12 \mathrm{~m}^{2}\right)$ and $0.95 \times 1.55 \mathrm{~m}$ $\left(1.5 \mathrm{~m}^{2}\right)$, and the thicknesses measured were $7,9,12$, and $21 \mathrm{~mm}$. Plywood samples of size $0.95 \times 1.55 \mathrm{~m}\left(1.5 \mathrm{~m}^{2}\right)$ with thicknesses of 15,17 , and $19 \mathrm{~mm}$ were also measured.

The small samples were clamped into a test frame using a steel box section and bolts around the perimeter. This resulted in an unsupported panel that had no studs present. The frame the sample is installed within is a heavy timber construction that is, in turn, bolted to a heavy concrete wall. The test aperture had a total depth of $550 \mathrm{~mm}$, and the sample arrangement resulted in a source room niche depth of $350 \mathrm{~mm}$.

The large samples were screwed and glued to a timber frame that was bolted into a test aperture. The edges and the joints between the panels were sealed with tape and silicone sealant. The test aperture had a total depth of $370 \mathrm{~mm}$, and the sample arrangement resulted in a source room niche depth of $160 \mathrm{~mm}$.

The same reverberation room was used for both sample sizes. It has a volume of $216 \mathrm{~m}^{3}$. Six stationary diffusing panels ensure the sound field is sufficiently diffuse. The total two-sided area of the diffusing elements is $13 \%$ of the total boundary surface area of the room. The total surface area of the reverberation room boundaries and diffusing elements is $305 \mathrm{~m}^{2}$. The receiving room for the small size samples was a small semi-anechoic room with a volume of $9 \mathrm{~m}^{3}$ and a surface area of $26.4 \mathrm{~m}^{2}$. This room is lined with sound absorption on all the surfaces except the floor, which is covered in deep pile carpet. The semi-anechoic receiving room for the large sample sizes has a volume of $200 \mathrm{~m}^{3}$ and a surface area of $236 \mathrm{~m}^{2}$. This receiving room is lined with sound absorptive materials on the walls and roof. The sound absorption in this room is increased by the addition of numerous hanging sound absorbers, resulting in a sound absorptive "tunnel." This is projected out from the sound insulation sample to increase the absorption of the emitted sound. The floor directly in front of the sample is also treated with a large number of sound absorptive panels that are laid down to reduce unwanted reflections. The large semi-anechoic room is a rectangular parallelepiped. The reverberation room and the small semi-anechoic room would be rectangular parallelepipeds except for the fact that one of their walls is angled so that it is not parallel with its opposite wall.

The sound pressure level was measured in the reverberation source room using six Brüel and Kjær (Nærum, Denmark) type 4189 half inch microphones. The source room was excited using a Brüel and Kjær 4269 sound source. The transmitted sound was measured on the receiving room side using a Brüel and Kjær intensity probe and Brüel and Kjær Pulse data acquisition equipment.

The intensity on the receiving room side was measured by performing two full surface scans at $150 \mathrm{~mm}$ from the sample surface, one horizontally and one vertically. The difference between these two scans was evaluated and the measurement was repeated if the difference was greater than one decibel in any of the one-third octave bands evaluated. The pressure-intensity index was also evaluated for each scan. If the pressure-intensity index was $>10 \mathrm{~dB}$ in any one-third octave band, the scan was repeated. This procedure was repeated five times for two source locations, yielding a total of ten sound insulation measurements. These were then averaged to provide the final sound insulation.

In order to perform predictions of the sound insulation of the different thickness plywood, their properties were required. Different estimates of these properties were made for each thickness of plywood. The Young's moduli in both orthotropic directions and the damping loss factor were evaluated using dynamic methods. The density was measured directly. It was found that the Young's moduli of the plywood were heavily dependent on the frequency of excitation.

The dependence of the Young's moduli on the frequency was found to be predicted with reasonable accuracy using an exponential decay. This decay curve was fitted to the frequency dependent stiffness values. An example of the curve for $12 \mathrm{~mm}$ plywood is shown in Fig. 1. This exponential function was incorporated into the equation for the sound transmission loss as a frequency dependent parameter. However, there is some scatter about the curves of best fit. This scatter is thought to be one of the reasons for the differences between the predicted and measured sound insulation. 


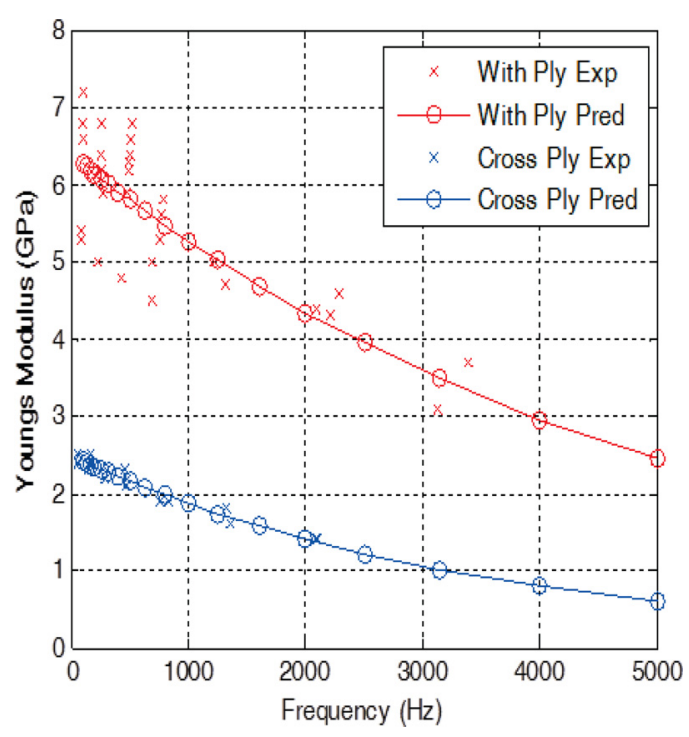

FIG. 1. (Color online) Measurements of the frequency dependent Young's moduli of $12 \mathrm{~mm}$ plywood and the associated curves of best fit used for predicting the frequency dependent Young's moduli.

\section{COMPARISON OF PREDICTIONS WITH EXPERIMENTAL RESULTS}

The sound insulation of $7,9,12$, and $21 \mathrm{~mm}$ thick plywood for the two different sample sizes and of 15, 17, and $19 \mathrm{~mm}$ thick plywood for the smaller sample size was predicted using four different methods described in Sec. II. Some of the differences between these methods are shown in Table I. The "isotropic" method was the simple isotropic method of Davy (2009a), modified as described in Sec. II, to include the effects of fluid loading. The "numerical imp." is the orthotropic method presented in Sec. II using numerical integration to calculate the radiation impedance, where imp. is an abbreviation for impedance. The "approx. imp." method is the orthotropic method presented in Sec. II using approximate formulas for the azimuthally averaged radiation impedance. These first three methods all use values of the Young's moduli that are constant with frequency. The variable E method is the approx. imp. method used with Young's moduli that vary with frequency according to best fit equations derived as described in Sec. II.

The comparison of these theoretical predictions with the experimental results is shown in Figs. 2-12. The four prediction methods agree well with each other for frequencies below the critical frequency region, although the predictions of the isotropic model for the large specimen size for all but

TABLE I. The names of the prediction methods used in this paper and the differences between them.

\begin{tabular}{lccc}
\hline \hline $\begin{array}{l}\text { Prediction } \\
\text { method }\end{array}$ & Orthotropic & $\begin{array}{c}\text { Approximate } \\
\text { radiation } \\
\text { impedance }\end{array}$ & $\begin{array}{c}\text { Variable } \\
\text { Young's } \\
\text { moduli }\end{array}$ \\
\hline Isotropic & No & Yes & No \\
Numerical imp. & Yes & No & No \\
Approx. imp. & Yes & Yes & No \\
Variable E & Yes & Yes & Yes \\
\hline \hline
\end{tabular}

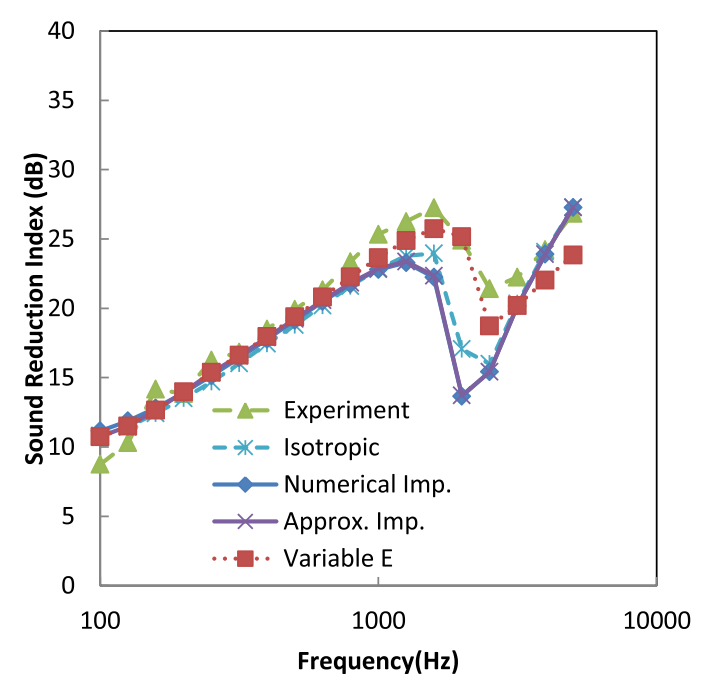

FIG. 2. (Color online) Comparison of the measured and predicted sound insulation of a $7 \mathrm{~mm}$ thick plywood panel measuring $0.95 \mathrm{~m}$ wide by $1.55 \mathrm{~m}$ high.

the $21 \mathrm{~mm}$ thick plywood do appear to be slightly but systematically lower than the other predictions in this frequency range. With the exception of the large $21 \mathrm{~mm}$ specimen, the agreement between theory and experiment in this low frequency range is also reasonable.

The numerical imp. method and the approx. imp. method agree very well with each other across the whole of the frequency range. This is the reason why the approx. imp. method was used as the basis for the variable E method. Except around the critical frequency region, the numerical imp. method and the approx. imp. method also agree well with the isotropic method, except for the small systematic departure described above, which occurs at low frequencies for the larger and thinner plywood specimens.

The variable $\mathrm{E}$ method agrees better with the experimental results in the critical frequency region for the 7 and

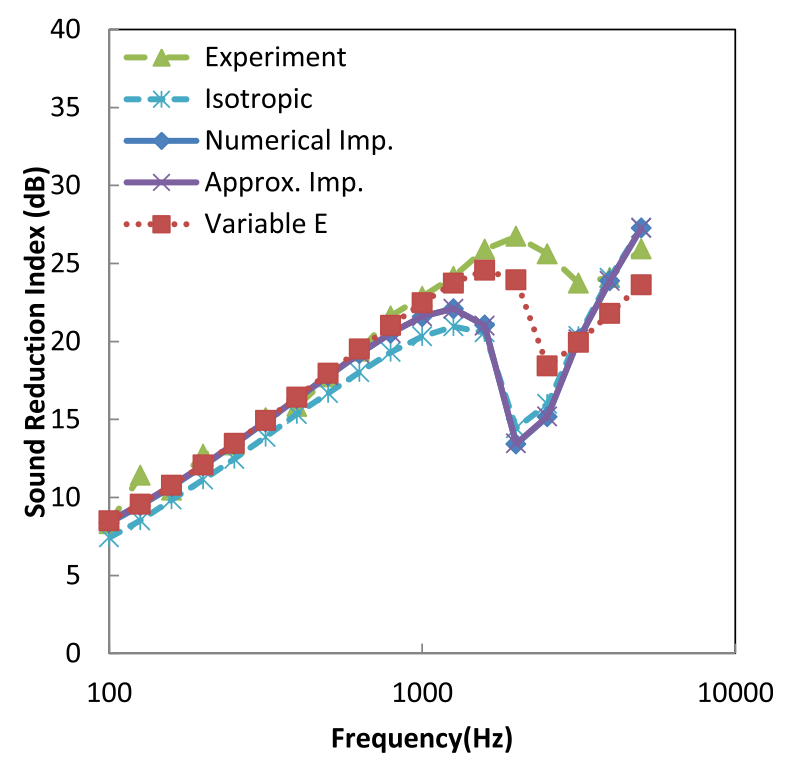

FIG. 3. (Color online) Comparison of the measured and predicted sound insulation of a $7 \mathrm{~mm}$ thick plywood panel measuring $4.8 \mathrm{~m}$ wide by $2.4 \mathrm{~m}$ high. 


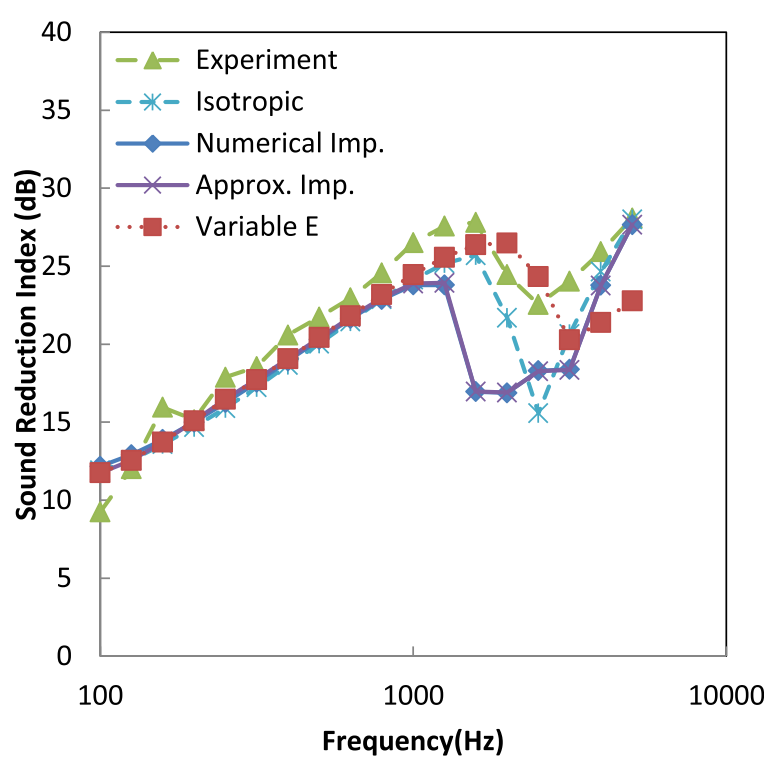

FIG. 4. (Color online) Comparison of the measured and predicted sound insulation of a $9 \mathrm{~mm}$ thick plywood panel measuring $0.95 \mathrm{~m}$ wide by $1.55 \mathrm{~m}$ high.

$9 \mathrm{~mm}$ thick plywood samples. With the exception of the large $21 \mathrm{~mm}$ specimen, the variable E method appears to require the use of a larger damping loss factor in order to make it agree with the experimental results above the critical frequency region. Thus, again with the exception of the large $21 \mathrm{~mm}$ specimen, the use of Young's moduli, which do not vary with frequency, gave better agreement above the critical frequency region.

All the prediction methods overestimated the depth of the critical frequency dip in the experimental data and did not always exactly predict the frequency of the minimum of the critical frequency dip, although the variable E method performed better in this regard than the other three methods in the cases of the 7 and $9 \mathrm{~mm}$ thick plywood. With the

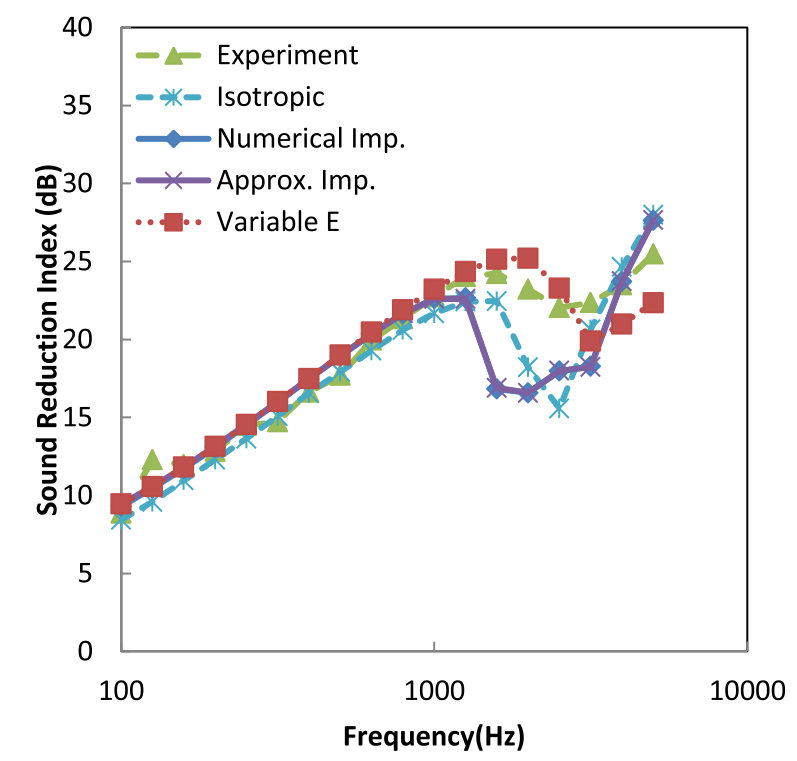

FIG. 5. (Color online) Comparison of the measured and predicted sound insulation of a $9 \mathrm{~mm}$ thick plywood panel measuring $4.8 \mathrm{~m}$ wide by $2.4 \mathrm{~m}$ high.

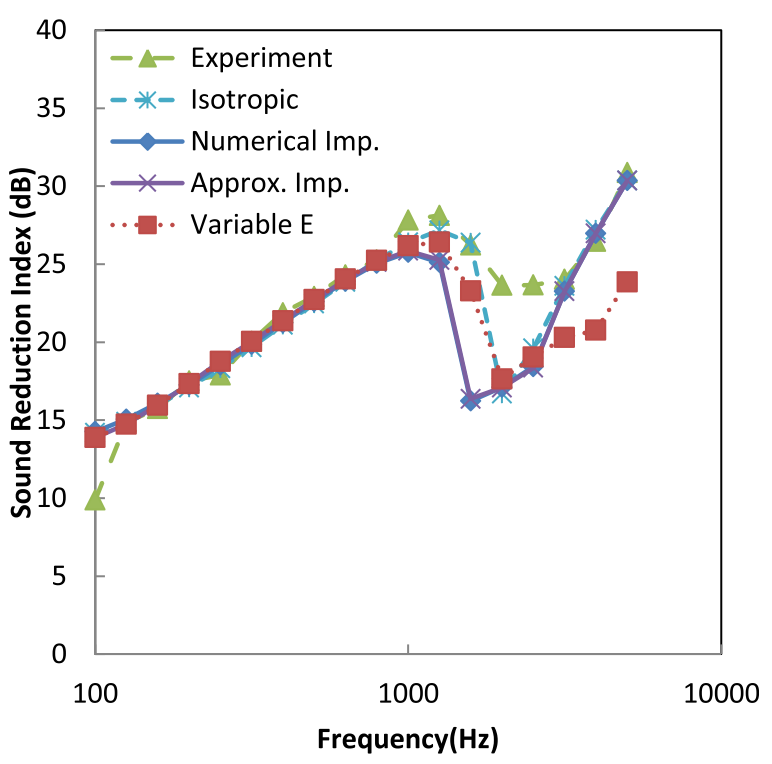

FIG. 6. (Color online) Comparison of the measured and predicted sound insulation of a $12 \mathrm{~mm}$ thick plywood panel measuring $0.95 \mathrm{~m}$ wide by $1.55 \mathrm{~m}$ high.

exception of the $7 \mathrm{~mm}$ thick plywood specimens, as expected, the isotropic method predicted narrower critical frequency dips than the other orthotropic prediction methods or the experimental measurements.

With the exception of low frequency values for the large $21 \mathrm{~mm}$ thick specimen, all the prediction methods performed reasonably well when predicting the changes in sound insulation due to the changes in specimen area. The predicted results using the same method for the small and large specimen sizes of the same thickness converge above the critical frequency region. This trend agrees with the measured results.

All the experimental results showed ripple in the low frequency region and this was more pronounced in the case

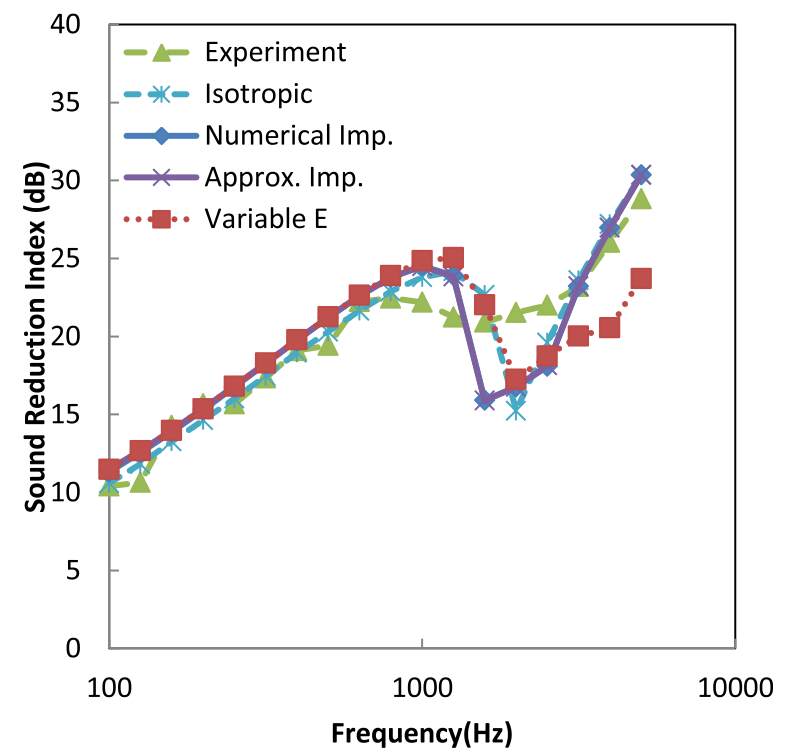

FIG. 7. (Color online) Comparison of the measured and predicted sound insulation of a $12 \mathrm{~mm}$ thick plywood panel measuring $4.8 \mathrm{~m}$ wide by $2.4 \mathrm{~m}$ high. 


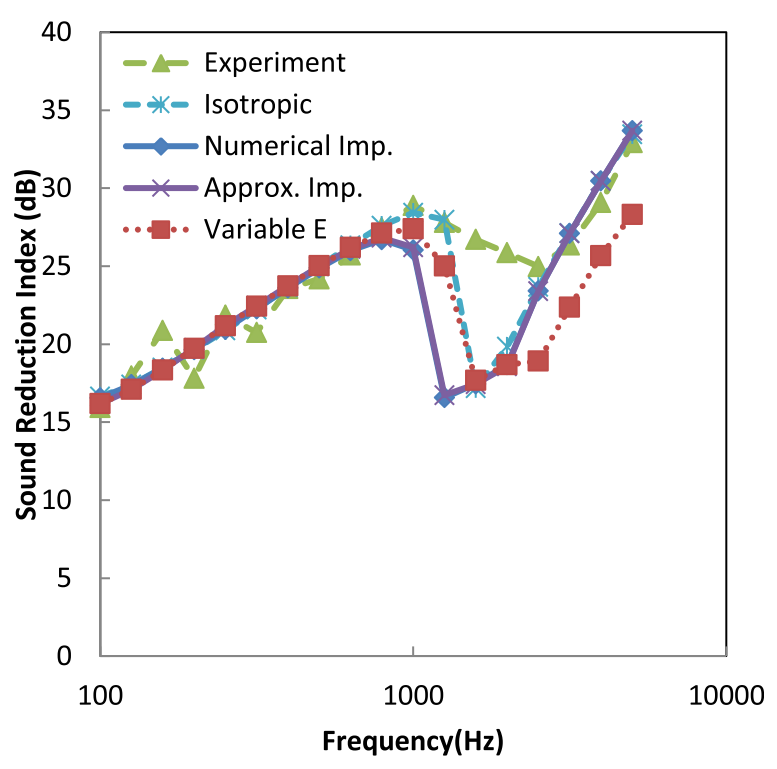

FIG. 8. (Color online) Comparison of the measured and predicted sound insulation of a $15 \mathrm{~mm}$ thick plywood panel measuring $0.95 \mathrm{~m}$ wide by $1.55 \mathrm{~m}$ high.

of the thicker specimens. Apart from possible experimental uncertainty, the authors are unsure why this phenomenon occurred.

In this paper, constant values of the damping loss factor as a function of frequency were used. This was also the case with the Young's moduli, except for the variable E method. It appears that a more accurate determination of the variability of the Young's moduli and the damping loss factor as a function of frequency is needed in order to improve the prediction of the sound insulation of orthotropic panels like plywood.

\section{SUMMARY AND CONCLUSIONS}

This paper presents a method for predicting the sound insulation of finite size rectangular single leaf orthotropic

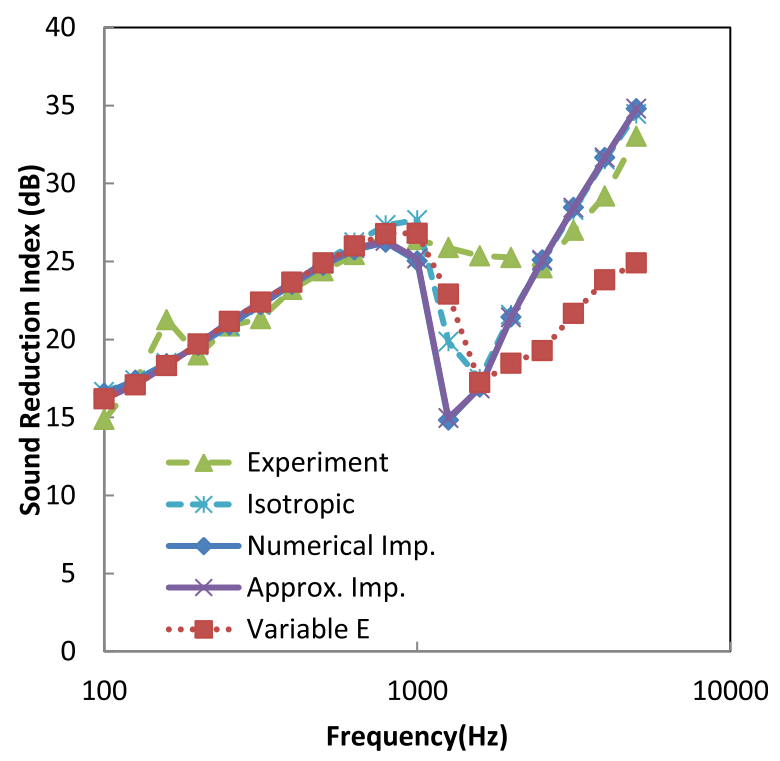

FIG. 9. (Color online) Comparison of the measured and predicted sound insulation of a $17 \mathrm{~mm}$ thick plywood panel measuring $0.95 \mathrm{~m}$ wide by $1.55 \mathrm{~m}$ high.

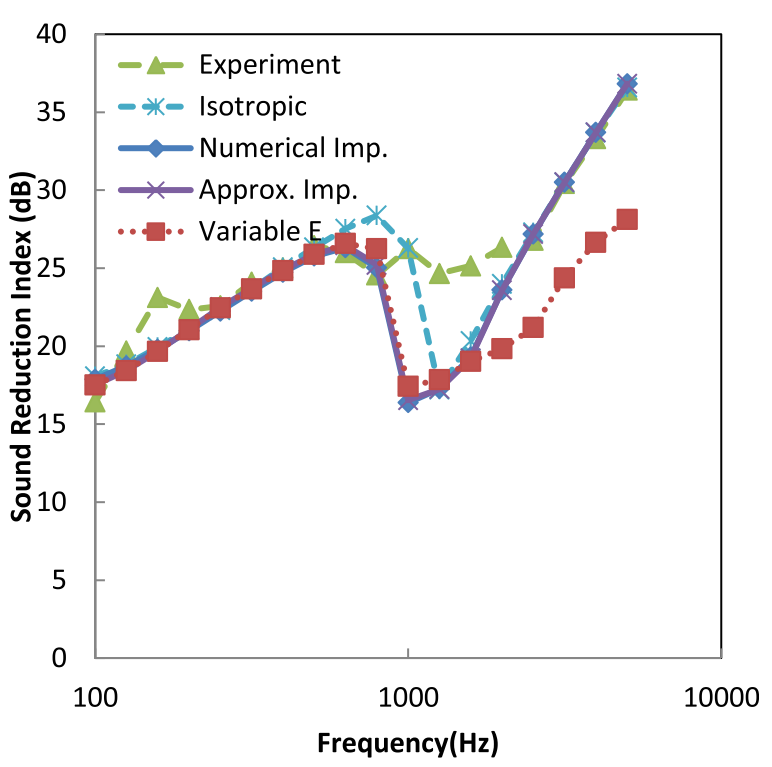

FIG. 10. (Color online) Comparison of the measured and predicted sound insulation of a $19 \mathrm{~mm}$ thick plywood panel measuring $0.95 \mathrm{~m}$ wide by $1.55 \mathrm{~m}$ high.

panels that involves the numerical evaluation of two nested integrals. This method was used with constant Young's moduli and an exact formula for the traveling wave radiation impedance. This exact formula included one integral that needs to be numerically evaluated and this led to the necessity to evaluate three nested integrals. The method was then used with constant Young's moduli and an approximate formula for the azimuthally averaged traveling wave radiation impedance. This reduced the number of nested integrals to two and substantially speeded up the numerical calculation. There was very little difference between the sound insulation predictions made using the exact formula and the approximate formula. The predictions were compared with experimental sound insulation measurements on small and large specimens of four different thicknesses of plywood and on another three

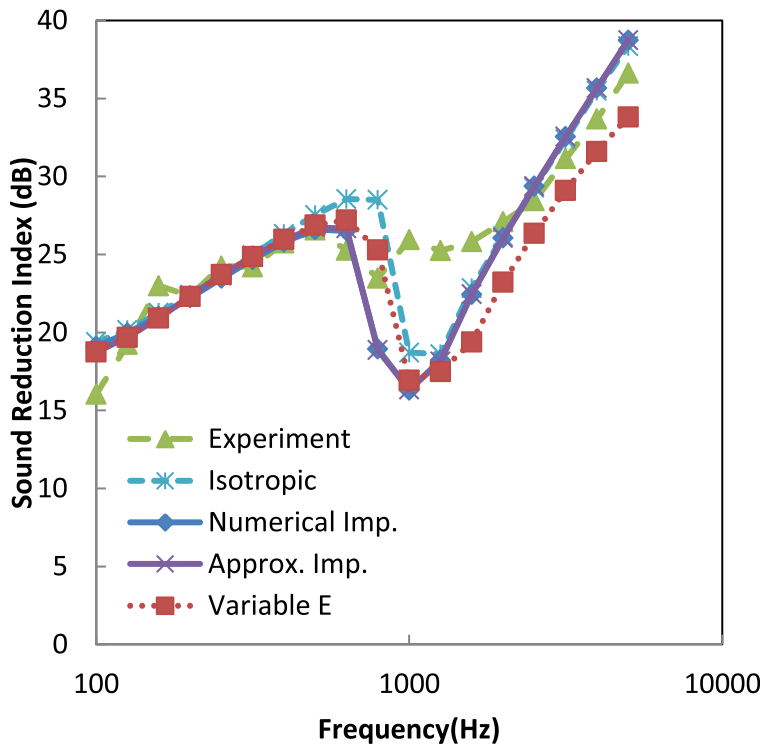

FIG. 11. (Color online) Comparison of the measured and predicted sound insulation of a $21 \mathrm{~mm}$ thick plywood panel measuring $0.95 \mathrm{~m}$ wide by $1.55 \mathrm{~m}$ high. 


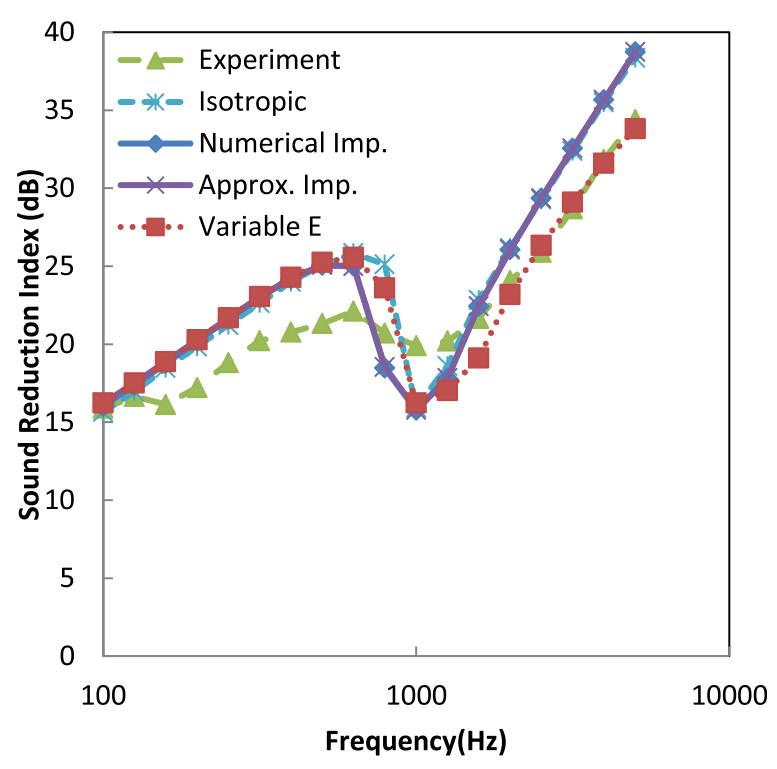

FIG. 12. (Color online) Comparison of the measured and predicted sound insulation of a $21 \mathrm{~mm}$ thick plywood panel measuring $4.8 \mathrm{~m}$ wide by $2.4 \mathrm{~m}$ high.

small specimens of other different thicknesses of plywood. Reasonable agreement was obtained except in the critical frequency region for all specimens and at low frequencies for the large specimen of the thickest plywood. A simple isotropic prediction method was also used to predict the sound insulation. This simple isotropic prediction method agreed well with the two previous predictions except in the critical frequency region where none of the three predictions agreed well with the experimental results. The simple isotropic prediction method also slightly but systematically underestimated the two previous predictions below the critical frequency region for the large specimens of the three thinnest plywood samples.

During testing of the material properties of the plywood panels, it was observed that the Young's moduli of the plywood panels were dependent on the frequency of excitation. Because of this observation, equations of best fit were derived for the Young's moduli. These equations of best fit for the Young's moduli were then used with the method presented in this paper and with the approximate formula for the azimuthally averaged traveling wave radiation impedance. The introduction of the frequency dependent Young's moduli significantly improved the predictions of sound insulation in the critical frequency region for the thinner 7 and $9 \mathrm{~mm}$ plywood specimens. It did not make as much difference in the critical frequency region for the other plywood specimens as had been expected. Above the critical frequency region, the use of the frequency dependent Young's moduli appeared to need the use of a larger damping loss factor in order to agree with the experimental results. The one exception to this was the large $21 \mathrm{~mm}$ plywood specimen for which there was good agreement in this high frequency range.

It appears that a more accurate assessment of the frequency dependence of the Young's moduli and the damping loss factor may improve the prediction of the sound insulation of mildly orthotropic panels like plywood. The simple isotropic model worked better than expected except in the critical frequency region where all the prediction methods struggled, especially with the thicker plywood samples.

Cherif, R., and Atalla, N. (2015). "Experimental investigation of the accuracy of a vibroacoustic model for sandwich-composite panels," J. Acoust. Soc. Am. 137, 1541-1550.

Craik, R. J. (1996). Sound Transmission through Buildings: Using Statistical Energy Analysis (Gower Aldershot, England), p. 261.

Cremer, L. (1942). "Theorie der schalldämmung wände bei schrägem einfall" ("Theory of the sound attenuation of thin walls with oblique incidence"), Akust. Z. 7, 81-104.

Crocker, M. J., and Price, A. J. (1969). "Sound transmission using statistical energy analysis," J. Sound Vib. 9, 469-486.

D'Alessandro, V., Petrone, G., Franco, F., and De Rosa, S. (2013). "A review of the vibroacoustics of sandwich panels: Models and experiments," J. Sandw. Struct. Mater. 15, 541-582.

Davy, J. L. (2009a). "Predicting the sound insulation of single leaf wallsExtension of Cremer's model," J. Acoust. Soc. Am. 126, 1871-1877.

Davy, J. L. (2009b). "Predicting the sound insulation of walls," Build. Acoust. 16, 1-20.

Davy, J. L., Larner, D. J., Wareing, R. R., and Pearse, J. R. (2015a). “The acoustic radiation impedance of a rectangular panel,” Build. Env. 92, 743-755.

Davy, J. L., Larner, D. J., Wareing, R. R., and Pearse, J. R. (2015b). "Approximate equations for the radiation impedance of a rectangular panel," in Inter-Noise 2015, San Francisco, CA (Institute of Noise Control Engineering, Reston, VA), p. 12.

Davy, J. L., Larner, D. J., Wareing, R. R., and Pearse, J. R. (2015c). "The radiation impedance of a rectangular panel," in Euronoise 2015 (Maastricht, The Netherlands), p. 6.

del Coz Diaz, J., Álvarez Rabanal, F., García Nieto, P., and Serrano López, M. (2010). "Sound transmission loss analysis through a multilayer lightweight concrete hollow brick wall by FEM and experimental validation," Build. Environ. 45, 2373-2386.

del Coz Diaz, J., García Nieto, P., Álvarez, F., and Suárez Sierra, J. (2007). "Evaluation of the acoustic behaviour of the light concrete hollow bricks by FEM and experimental validation," in Proceedings of the CIATEA Conference, Ediuno, pp. 27-29.

Fahy, F. J. (1994). "Statistical energy analysis: A critical overview," Philos. Trans. R. Soc., A 346, 431-447.

Feng, L., and Kumar, S. (2012). "On application of radiation loss factor in the prediction of sound transmission loss of a honeycomb panel," Int. J. Acoust. Vib. 17, 47-51, available at http://iiav.org/ijav/content/volumes/ 17_2012_1469441332161031/vol_1/233_firstpage_960501336384400.pdf.

Guyader, J. L., and Lesueur, C. (1978a). "Acoustic transmission through orthotropic multilayered plates, part I: Plate vibration modes," J. Sound Vib. 58, 51-68.

Guyader, J. L., and Lesueur, C. (1978b). "Acoustic transmission through orthotropic multilayered plates, part II: Transmission loss," J. Sound Vib. $\mathbf{5 8}, 69-86$.

Guyader, J. L., and Lesueur, C. (1980). "Transmission of reverberant sound through orthotropic, viscoelastic multilayered plates," J. Sound Vib. 70, 319-332.

Hansen, C. H. (1990). "Sound transmission loss of fluted and corrugated panels-damped and undamped," in Interior Noise Climates (Australian Acoustical Society, Perth), pp. 5.1-5.18.

Hansen, C. H. (1991). "Effect of size on the sound transmission loss of both heavily and lightly damped orthotropic panels," in INTER-NOISE Conference Proceedings, Institute of Noise Control Engineering, pp. 263-266.

Hongisto, V. (2006). "Sound insulation of double panels-comparison of existing prediction models," Acta. Acust. Acust. 92, 61-78, available at http://www.ingentaconnect.com/content/dav/aaua/2006/00000092/00000001/ art00008.

Hongisto, V., Lindgren, M., and Helenius, R. (2002). "Sound insulation of double walls-An experimental parametric study," Acta. Acust. Acust. 88, 904-923, available at http://www.ingentaconnect.com/content/dav/ aaua/2002/00000088/00000006/art00010.

ISO (2000). ISO 15186-1:2000, "Acoustics-Measurement of sound insulation in buildings and of building elements using sound intensity-Part 1: Laboratory" (International Organization for Standardization, Geneva, Switzerland), pp. 1-20. 
Kuo, Y.-M., Lin, H.-J., and Wang, C.-N. (2008). "Sound transmission across orthotropic laminates with a 3D model," Appl. Acoust. 69, 951-959.

Lee, C. M., and Xu, Y. (2009). "A modified transfer matrix method for prediction of transmission loss of multilayer acoustic materials," J. Sound Vib. 326, 290-301.

Leissa, A. W. (1969). "Vibration of plates," Technical Report No. NASASP-160 (NASA, Washington, DC), 362 pp., available at http://ntrs.nasa. gov/search.jsp?R=19700009156.

London, A. (1949). "Transmission of reverberant sound through single walls," J. Res. Natl. Bur. Stand. 42, 605-615.

London, A. (1950). "Transmission of reverberant sound through double walls," J. Acoust. Soc. Am. 22, 270-279.

Ordubadi, A., and Lyon, R. H. (1979). "Effect of orthotropy on the sound transmission through plywood panels," J. Acoust. Soc. Am. 65, 133-139.

Orrenius, U. E., Wareing, A., and Kumar, S. (2010). "Prediction and control of sound transmission through honeycomb sandwich panels for aircraft fuselage and train floors," in The 17th International Congress on Sound and Vibration (ICSV17) (International Institute of Acoustics and Vibration, Cairo, Egypt), pp. 117-124.
Rhazi, D., and Atalla, N. (2010). "A simple method to account for size effects in the transfer matrix method," J. Acoust. Soc. Am. 127, EL30-EL36.

Sastry, J., and Munjal, M. (1995). "A transfer matrix approach for evaluation of the response of a multi-layer infinite plate to a two-dimensional pressure excitation," J. Sound Vib. 182, 109-128.

Sewell, E. (1970). "Transmission of reverberant sound through a single-leaf partition surrounded by an infinite rigid baffle," J. Sound Vib. 12, 21-32.

Sharp, B. H. (1978). "Prediction methods for the sound transmission of building elements," Noise Control Eng. 11, 53-63.

Steel, J., and Craik, R. (1994). "Statistical energy analysis of structure-borne sound transmission by finite element methods," J. Sound Vib. 178, 553-561.

Trevathan, J. (2005). "Sound transmission through walls: A coupled BEM/ FEM approach," Ph.D. thesis, Department of Mechanical Engineering, University of Canterbury, Christchurch, New Zealand, p. 664.

Woodcock, R., and Nicolas, J. (1995). "A generalized model for predicting the sound transmission properties of generally orthotropic plates with arbitrary boundary conditions," J. Acoust. Soc. Am. 97, 1099-1112. 